\title{
Effect of Formate on Volume Reabsorption in the Rabbit Proximal Tubule
}

\author{
Laurent Schild, Gerhard Giebisch, Lawrence P. Karniski, and Peter S. Aronson \\ Departments of Physiology and Internal Medicine, Yale University School of Medicine, New Haven, Connecticut 06510
}

\begin{abstract}
Studies on microvillus membrane from rabbit kidney cortex suggest that chloride absorption may occur by chloride/formate exchange with recycling of formic acid by nonionic diffusion. We tested whether this transport mechanism participates in active $\mathrm{NaCl}$ reabsorption in the rabbit proximal tubule.

In proximal tubule $\mathrm{S} 2$ segments perfused with low $\mathrm{HCO}_{3}^{-}$ solutions, the addition of formate (0.25- $0.5 \mathrm{mM})$ to the lumen and the bath increased volume reabsorption $\left(\mathrm{J}_{V}\right)$ by $60 \%$; the transepithelial potential difference remained unchanged. The effect of formate on $J_{V}$ was completely reversible and was inhibited both by ouabain and by luminal 4,4'-diisothiocyanostilbene-2,2'disulfonate.

Formate (0.5 mM) failed to stimulate $\mathrm{J}_{V}$ in early proximal convoluted tubules perfused with high $\mathrm{HCO}_{3}^{-}$solutions. As measured by miniature glass $\mathrm{pH}$ microelectrodes, this lack of formate effect on $J_{V}$ was related to a less extensive acidification of the tubule fluid when high $\mathrm{HCO}_{3}^{-}$solutions were used as perfusate. These data suggest that chloride/formate exchange with recycling of formic acid by nonionic diffusion represents a mechanism for active, electroneutral $\mathrm{NaCl}$ reabsorption in the proximal tubule.
\end{abstract}

\section{Introduction}

In the early portion of the proximal tubule of the mammalian kidney, isotonic volume reabsorption $\left(J_{V}\right)^{1}$ is associated with preferential reabsorption of bicarbonate and organic solutes (1, 2 ). This results in increased chloride concentration in the later portion of the proximal tubule and a shift of the transepithelial potential from lumen negative to lumen positive. The generation of a chloride diffusion potential by the transepithelial chloride gradient reflects a relatively large conductance for $\mathrm{Cl}^{-}$, most probably across the intercellular pathway $(3,4)$. Given the favorable passive driving force for $\mathrm{Cl}^{-}$in the late proximal tubule, it is thought that a significant fraction of $\mathrm{Cl}^{-}$reabsorption occurs passively.

On the other hand, chloride reabsorption across the proximal tubule has also been shown to continue in the absence of any passive driving force for chloride $(5,6)$. This suggests an active, transcellular mechanism of chloride reabsorption. It has been

Part of this material has been presented in abstract form. (1986. Kidney Int., 29:407a.)

Dr. Karniski's present address is Department of Internal Medicine, University of Iowa, Iowa City, IA 52242.

Received for publication 22 May 1986.

1. Abbreviations used in this paper: DIDS, 4,4'-diisothiocyanostilbene2,2'-disulfonate; $\mathrm{J}_{V}$, volume reabsorption; Vte, transepithelial potential difference.

J. Clin. Invest.

(c) The American Society for Clinical Investigation, Inc. 0021-9738/87/01/0032/07 \$1.00

Volume 79 , January $1987,32-38$ proposed that transcellular, electroneutral $\mathrm{NaCl}$ transport is involved in this component of chloride reabsorption, but little is known about its specific mechanism (7).

On the basis of studies on rabbit renal cortical microvillus membrane vesicles, Karniski and Aronson have suggested that chloride/formate exchange with recycling of formic acid by nonionic diffusion could be a potential mechanism for active $\mathrm{Cl}^{-}$transport across the luminal membrane (8). If this anion exchanger were to operate in parallel with $\mathrm{Na}^{+} / \mathrm{H}^{+}$antiport, coupled electroneutral $\mathrm{NaCl}$ reabsorption would take place.

Our experiments were designed to test whether electroneutral formate/chloride exchange plays a significant role in proximal chloride reabsorption. The present study was performed to test the following four predictions.

Physiological concentrations of formate should reversibly stimulate $\mathrm{J}_{V}$ without changes in the transepithelial potential.

The formate-stimulated $\mathrm{J}_{V}$ should be subject to inhibition both by $4,4^{\prime}$-diisothiocyanostilbene-2,2'-disulfonate (DIDS), an inhibitor of formate/chloride exchange in renal microvillus membrane vesicles, and by ouabain, the inhibitor of active $\mathrm{Na}$ transport.

Stimulation of $\mathrm{J}_{V}$ by formate should be demonstrable in the absence of any passive driving force for $\mathrm{Cl}$.

Formate-induced water reabsorption should be affected by luminal $\mathrm{pH}$, to the extent that recycling of formic acid by nonionic diffusion is rate limiting for formate/chloride exchange and thus also for $\mathrm{NaCl}$ reabsorption.

Our study demonstrates that these four predictions were accurate.

\section{Methods}

Preparation and perfusion of isolated tubules in vitro. Segments of rabbit proximal tubules were isolated and perfused in vitro with techniques first described by Burg et al. (9). Briefly, New Zealand White rabbits weighing $1.5-2 \mathrm{~kg}$ were used. The right kidney was rapidly removed and cut in coronal slices $\sim 0.5 \mathrm{~mm}$ thick. The dissection was done at $4^{\circ} \mathrm{C}$ in an ultrafiltratelike solution containing $1 \mathrm{~g} / 100 \mathrm{ml}$ albumin, buffered at $\mathrm{pH} 7.4$ with Hepes and gassed with $100 \% \mathrm{O}_{2}$.

Two different segments of the proximal tubule were used in this study. S2 segments, which include the last convolutions and the beginning of the pars recta of the proximal tubule, were dissected using bundles radiating from the cortico-medullary junction to the surface of the cortex. Only tubules reaching the kidney surface, S2 superficial tubules, were used. Early proximal convoluted tubules, defined as $\mathbf{S 1}$ segments, were selected on the basis of their attachment to the glomerulus and their localization in the superficial cortex. The dissected tubules were transferred into a temperature-regulated Lucite chamber containing $2 \mathrm{ml}$ of bathing solution at $37^{\circ} \mathrm{C}$ (see Table I) and mounted between appropriate concentric pipettes. The flow rate of the perfusion was regulated by gravity (hydrostatic pressure, $15-20 \mathrm{~cm} \mathrm{H}_{2} \mathrm{O}$ ) to maintain a tubular perfusion rate between 10 and $20 \mathrm{nl} / \mathrm{min}$. Net $J_{V}$ (nanoliter $\cdot$ minute $^{-1} \cdot$ millimeter $^{-1}$ ) was determined as the difference between the calculated perfusion rate and the measured collection rate. The collection rate was measured by collecting samples of the perfusate over timed intervals in calibrated constriction pipettes with a volume $>50 \mathrm{nl}$. Exhaustively dialyzed meth- 
Table I. Composition of Solutions

\begin{tabular}{|c|c|c|c|c|}
\hline & \multicolumn{2}{|l|}{ Bath } & \multicolumn{2}{|l|}{ Perfusate } \\
\hline & Control & $\begin{array}{l}\text { Low } \mathrm{HCO}_{3}^{-} \text {, } \\
\text { high } \mathrm{Cl}^{-}\end{array}$ & $\begin{array}{l}\text { Low } \mathrm{HCO}_{3}^{-} \text {, } \\
\text { high } \mathrm{Cl}^{-}\end{array}$ & $\begin{array}{l}\text { High } \mathrm{HCO}_{3}^{-} \text {, } \\
\text { low } \mathrm{Cl}^{-}\end{array}$ \\
\hline $\mathrm{NaCl}$ & 115 & 135 & 135 & 115 \\
\hline $\mathrm{NaHCO}_{3}$ & 20 & 4 & 4 & 20 \\
\hline $\mathrm{NaH}_{2} \mathrm{PO}_{4}$ & 4 & 4 & 4 & 4 \\
\hline $\mathrm{KCl}$ & 5 & 5 & 5 & 5 \\
\hline $\mathrm{CaCl}_{2}$ & 1.8 & 1.8 & 1.8 & 1.8 \\
\hline $\mathrm{MgSO}_{4}$ & 1 & 1 & 1 & 1 \\
\hline Acetate & 5 & 5 & - & - \\
\hline Glucose & 5 & 5 & - & - \\
\hline Alanine & 5 & 5 & - & - \\
\hline Mannitol & - & - & 15 & 15 \\
\hline $\begin{array}{l}\text { Albumin } \\
\mathrm{CO}_{2}\end{array}$ & $\begin{array}{l}6 \mathrm{~g} / 100 \mathrm{ml} \\
5 \%\end{array}$ & $\begin{array}{l}6 \mathrm{~g} / 100 \mathrm{ml} \\
1 \%\end{array}$ & $\overline{5 \%}$ or $1 \%$ & - \\
\hline
\end{tabular}

oxy- $\left[{ }^{3} \mathrm{H}\right]$ inulin (New England Nuclear, Boston, MA) was used as volume marker and added to the perfusate at a concentration of $20 \mu \mathrm{Ci} / \mathrm{ml}$. The perfusion rate was calculated from the collection rate and from the difference of inulin concentration between the perfusate and the collectate.

The compositions of the perfusion solutions and the bath solutions are listed in Table I. S2 segments of proximal tubules were perfused with a high-chloride, low-bicarbonate solution similar in composition to late proximal tubule fluid. Solutions simulating serum and containing $6 \mathrm{~g} /$ $100 \mathrm{ml}$ albumin were used as bath solution. S1 segments were perfused and bathed with symmetrical solutions containing either 20 or $4 \mathrm{mM}$ $\mathrm{HCO}_{3}^{-}$. To obtain the same $\mathrm{pH}$ (7.30 to 7.35), the serumlike bath solutions were bubbled with either $95 \% \mathrm{O}_{2}-5 \% \mathrm{CO}_{2}$ or $99 \% \mathrm{O}_{2}-1 \% \mathrm{CO}_{2}$ gas mixture. Dialyzed albumin (BSA Fraction V; Sigma Chemical Co., St. Louis, MO) was added to the bath solution at a concentration of $6 \mathrm{~g} / 100 \mathrm{ml}$. No organic substrates were present in the perfusion solutions. All solutions were adjusted to a total osmolality of $300 \mathrm{mosmol} / \mathrm{kg} \mathrm{H}_{2} \mathrm{O}$ by adding $\mathrm{H}_{2} \mathrm{O}$ or $\mathrm{NaCl}$ salt.

During the experiments, bathing solutions continuously flowed through the chamber at a rate of $\sim 0.3 \mathrm{ml} \cdot \mathrm{min}^{-1}$. The solutions were preheated through tubing at a temperature of $40^{\circ} \mathrm{C}$, and the bath temperature was maintained in the chamber at $38^{\circ} \mathrm{C}$ with a specially designed temperature-regulating system. The bath was continuously bubbled with the appropriate gas mixtures, and its $\mathrm{pH}$ was continuously monitored with a miniature pH electrode (Beetrode; World Precision Instruments, Inc., New Haven, CT) placed in the vicinity of the tubule.

The protocols were designed to study the effects of formate and different transport inhibitors on water reabsorption and the transepithelial potential difference in the proximal tubule. The first collection began after an equilibration time of $30 \mathrm{~min}$, to be followed by several experimental periods. Before starting collections, the holding pipette was carefully rinsed and the first collected sample was discarded. The tubular collections were performed for at least $10 \mathrm{~min}$ to obtain a minimum of two samples per period. Tubules were discarded if irreversible morphological changes such as cell swelling or cell granulation occurred during the experiment.

Transepithelial potential difference measurements. The transepithelial potential difference (Vte) was measured as in previous studies performed in this laboratory (10). The perfusion pipette was used as a bridge to the tubular lumen; the perfusion solution and the bath were connected to calomel electrodes via $150 \mathrm{mM} \mathrm{NaCl}$-agarose bridges. The potential difference of this circuit was measured with a high-impedance electrometer (model 750; World Precision Instruments, Inc.). The output of the electrometer was displayed on a digital voltmeter (Newport Electronics, Inc., Santa Ana, CA) and a strip chart recorder (model 220; Gould, Inc., Cleveland, $\mathrm{OH}$ ). With no tubule in place this system was stable for several hours. The reference baseline potential, measured at $38^{\circ} \mathrm{C}$ in the absence of a tubule, never exceeded $0.5 \mathrm{mV}$. Correction of the liquid junction potential was made in the following way. Before mounting a tubule between the pipettes, the measured small circuit potential was compensated and the potential was set to zero when the chamber was filled with the bath at $37^{\circ} \mathrm{C}$. The perfusion pipette contained the perfusate. The tubule was then mounted and cannulated, and the change in circuit potential was recorded as the transepithelial potential. Tubules were perfused uniformly throughout the experiments with solutions of identical ionic composition, or with such additions as submillimolar concentrations of transport inhibitors and formate or acetate. Accordingly, corrections for changes in liquid junction potentials were minimized in our experimental settings.

pH measurements of the tubular fluid. $\mathrm{pH}$-sensitive glass electrodes were used to measure the $\mathrm{pH}$ of the tubular fluid at the distal end of the perfused tubule. The pH-sensitive glass electrodes were constructed by fusing pH-sensitive glass (World Precision Instruments, Inc.) to the tip of a non-pH-sensitive glass capillary (Drummond Scientific Co., Broomall, PA) to form a bulb with a diameter of $\sim 40-50 \mu \mathrm{m}$. This miniature $\mathrm{pH}$ electrode was filled with a citrate $\mathrm{pH}$ buffer $(\mathrm{pH} \mathrm{6)}$ and connected via an electrode holder (World Precision Instruments, Inc.) to a high impedance amplifier (model 750; World Precision Instruments, Inc.). The electrodes were calibrated before and after the experiments in a standard buffer solution. The slope of the $\mathrm{pH}$ electrode was $59.09 \pm 1.8$ $\mathrm{mV} / \mathrm{pH} \mathrm{U}$ (mean $\pm \mathrm{SD}$ ). The $\mathrm{pH}$ electrode assembly was inserted into the collecting pipette. Its shape was modified by a constriction at the tip of the pipette to accommodate the $\mathrm{pH}$ electrode. This made it possible to measure the $\mathrm{pH}$ of the emerging tubular fluid in a small compartment $(100 \mathrm{nl})$. This minimized loss of $\mathrm{CO}_{2}$ from the collected fluid (11). The $\mathrm{pH}$ of the initial perfusion fluid was measured by two methods. The first was to measure $\mathrm{pH}$ in the collection pipette assembly when tubules were perfused under pressure at very high flow rate (in excess of $600 \mathrm{nl} / \mathrm{min}$ ), because $\mathrm{pH}$ changes by tubule activity are virtually abolished under these conditions. This was demonstrated directly, as the $\mathrm{pH}$ values so obtained were not different from values measured with the miniature glass $\mathrm{pH}$ electrode in the initial perfusion fluid, bubbled with the appropriate gas mixture.

Statistics. The results are expressed as the mean $\pm \mathrm{SE}$ of individual measurements. In general, paired experiments were performed. Thus, when appropriate, the mean paired $t$ test was used (12).

\section{Results}

A summary of the effect of formate on transepithelial water reabsorption and on Vte across the $\mathrm{S} 2$ segment of the proximal tubule is presented in Fig. 1. Significant net fluid absorption is apparent during perfusion of S2 segments with high-chloridelow-bicarbonate solutions and a bath solution containing $20 \mathrm{mM}$ $\mathrm{HCO}_{3}^{-}$. Addition of formate in submillimolar concentrations, 0.5 and $0.25 \mathrm{mM}$ to the bath and the lumen, increased $J_{V}$ significantly, from $0.58 \pm 0.08 \mathrm{nl} \cdot \mathrm{min}^{-1} \cdot \mathrm{mm}^{-1}$ (mean $\pm \mathrm{SE}$ ) to $0.94 \pm 0.08 \mathrm{nl} \cdot \mathrm{min}^{-1} \cdot \mathrm{mm}^{-1}($ mean $\pm \mathrm{SE})$ and from $0.38 \pm 0.03$ $\mathrm{nl} \cdot \mathrm{min}^{-1} \cdot \mathrm{mm}^{-1}($ mean $\pm \mathrm{SE})$ to $0.63 \pm 0.04 \mathrm{nl} \cdot \mathrm{min}^{-1} \cdot \mathrm{mm}^{-1}$ (mean $\pm \mathrm{SE}$ ), respectively. ${ }^{2}$ Since the perfusion solution contains

2. The mean value of $\mathrm{J}_{V}$ obtained in the $\mathrm{S} 2$ segment was $0.47 \mathrm{nl} /$ $\mathrm{min} \cdot \mathrm{mm} \pm 0.05 \mathrm{nl} / \mathrm{min} \cdot \mathrm{mm}$ (mean $\pm \mathrm{SE}$ ). This value is between $0.56 \mathrm{nl} /$ $\min \cdot \mathrm{mm}$, reported by Berry in the proximal convoluted tubule (1983, J. Clin. Invest. $71: 268-281$.) and $0.38 \mathrm{nl} / \mathrm{min} \cdot \mathrm{mm}$, reported by Schafer et al. in the pars recta of rabbit kidney (1981. Kidney Int. 20:588-597.) It is likely that our mean value of $J_{V}$ obtained in the $S 2$ segment reflects the transition between the proximal convoluted and straight tubule. We also note the difference in $J_{V}$ between the two control groups using low and high formate concentration. We have no explanation for this difference, but the design of our experiment includes the use of paired samples, each tubule serving as its own control. 
$\mathrm{J}_{\mathrm{v}}(\mathrm{nl} / \mathrm{min} \cdot \mathrm{mm})$

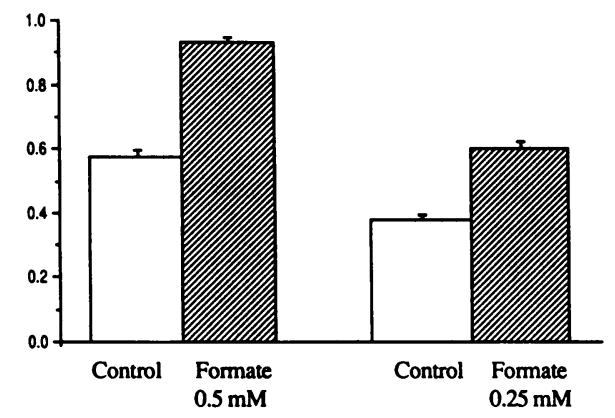

$\mathrm{V}_{\mathrm{te}}(\mathrm{mV})$

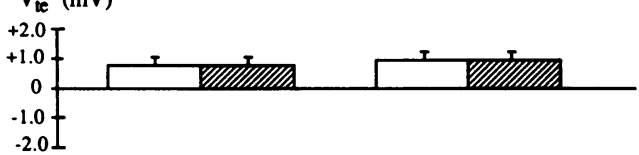

Figure 1. Effect of formate, $0.5 \mathrm{mM}(n=10)$ and $0.25 \mathrm{mM}(n=13)$, added to the bath and the lumen on $J_{V}$ and Vte. S2 segments of the proximal tubule were perfused with low $\mathrm{HCO}_{3}^{-}$solutions simulating late proximal tubule fluid. The bath contained $20 \mathrm{mM} \mathrm{HCO}_{3}^{-}$. In the control conditions and after the addition of formate the mean perfusion rates were $14.27 \pm 4$ and $14.56 \pm 2.2 \mathrm{nl} / \mathrm{min}$ (mean $\pm \mathrm{SE}$ ), respectively.

mainly $\mathrm{NaCl}$, we conclude that the increase in $\mathrm{J}_{V}$ reflects stimulation of $\mathrm{NaCl}$ transport.

The Vte was positive during the control period and remained unchanged after the addition of formate, 0.5 and $0.25 \mathrm{mM}$, to the bath and lumen. The lumen positive potential under these experimental conditions reflects the diffusion potential due to the passive, intercellular movement of $\mathrm{Cl}^{-}$across the epithelium $(4,5,7,13)$. The failure of Vte to change in parallel with the increase in $J_{V}$ suggests that formate stimulates an active, electroneutral component of $\mathrm{NaCl}$ transport, and that formate does not affect the passive paracellular component of $\mathrm{Cl}^{-}$movement across the epithelium.

As shown in Fig. 2, the increase in water reabsorption induced by formate was fully reversible. Thus, formate at the concentrations used in these experiments did not cause irreversible alteration of the tubular epithelium. To rule out a nonspecific metabolic effect as responsible for stimulation of $\mathrm{J}_{V}$ by formate, we measured $\mathrm{J}_{V}$ after addition of $0.5 \mathrm{mM}$ acetate to the bath and the lumen. As illustrated in Fig. 3, $0.5 \mathrm{mM}$ acetate had no significant effect on transepithelial water reabsorption. These data suggest that formate increases the reabsorption of water in the proximal tubule by stimulating a specific electroneutral transport mechanism.

The effects of two transport inhibitors, ouabain and DIDS, were also investigated. As shown in Figs. 4 and 5, these agents significantly modify the effects of formate on proximal fluid transport. The results of experiments performed on S2 segments perfused with solutions simulating late proximal tubule fluid are shown. Ouabain, at a concentration of $0.05 \mathrm{mM}$, suppressed the increase in $J_{V}$ due to addition of formate to the bath and the lumen. Transepithelial fluid reabsorption was not completely abolished by ouabain because a favorable passive driving force for $\mathrm{NaCl}$ absorption was present $(4,14)$. However, $J_{V}$ in the presence of ouabain was significantly lower $(P=0.018)$ than that observed during the control period in which active transport was present. The transepithelial potential difference remained
$\mathrm{J}_{\mathbf{v}}(\mathrm{nl} / \mathrm{min} \cdot \mathrm{mm})$
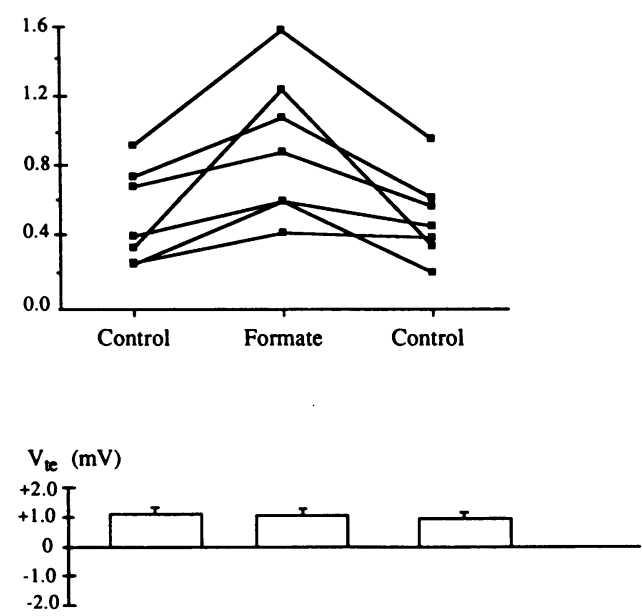

Figure 2. Reversibility of the effect of formate $(0.5$ and $0.25 \mathrm{mM})$ in the bath and lumen on $J_{V}$ and Vte. S2 segments of the proximal tubule were perfused with low $\mathrm{HCO}_{3}^{-}$solutions and bathed with a solution containing $20 \mathrm{mM} \mathrm{HCO}_{3}^{-}$.

positive and unchanged after inhibition of active transport by ouabain. Again this confirms that an important component of $\mathrm{NaCl}$ transport is active and electroneutral and can be stimulated by formate. The addition of the anion-exchange inhibitor DIDS to the tubular lumen at a concentration of $1 \mathrm{mM}$, also suppressed the stimulation of $J_{V}$ induced by formate. This inhibitory effect of DIDS is consistent with participation of a specific anion-exchange mechanism in the stimulation of $\mathrm{NaCl}$ transport by formate. Interestingly, water reabsorption during perfusion with luminal DIDS was significantly lower than that in the control period $(P=0.003)$. The observation that the lumen positive transepithelial potential difference dropped to 0 after addition of DIDS suggests that DIDS, at a concentration of $1 \mathrm{mM}$, may decrease the passive movement of chloride via the paracellular shunt pathway in addition to inhibiting the luminal membrane anion exchanger. This interpretation is consistent with the suppression of $\mathrm{J}_{V}$ below control values by DIDS, because a reduction of the transepithelial chloride permeability would interfere with that component of transepithelial fluid movement driven by the chloride gradient.

The experiments described so far were performed in the S2 proximal tubules perfused with a solution simulating late prox-

$\mathrm{J}_{\mathrm{v}}(\mathrm{nl} / \mathrm{min} \cdot \mathrm{mm})$

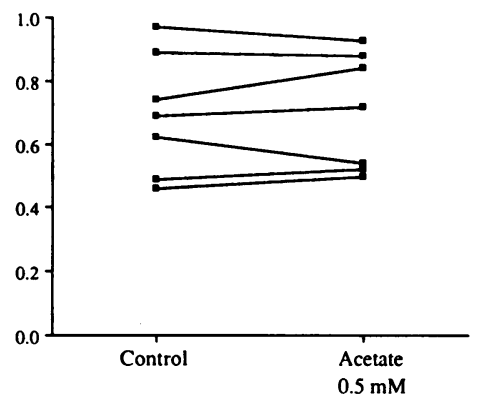

Figure 3. Effect of addition of $0.5 \mathrm{mM}$ acetate to the perfusate and the bath on $\mathrm{J}_{V}$. S2 segments of the proximal tubule were perfused with low $\mathrm{HCO}_{3}^{-}$solutions and bathed in a solution containing $20 \mathrm{mM}$ $\mathrm{HCO}_{3}^{-}$. 

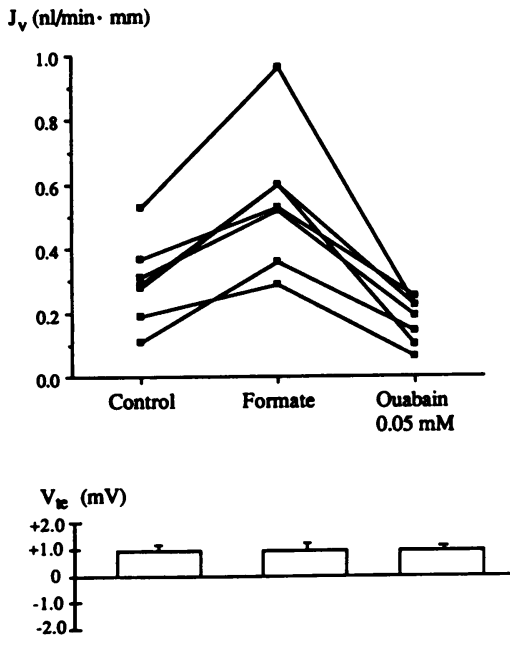

Figure 4. Effect of ouabain $(0.05 \mathrm{mM}$ in the bath) on $J_{V}$ and $V$ te in S2 segments of the proximal tubule in the presence of formate $(0.5$ and $0.25 \mathrm{mM}$ ), in the perfusion fluid and the bath. The perfusion fluid and the bath contained 4 and $20 \mathrm{mM} \mathrm{HCO}_{3}^{-}$, respectively. imal fluid. In a second protocol we examined the ability of formate to stimulate $\mathrm{NaCl}$ reabsorption in the early proximal convoluted tubule (segment $\mathrm{S} 1$ ), in which transepithelial gradients of $\mathrm{Cl}$ and bicarbonate were initially absent.

Early proximal convoluted tubules were perfused and bathed with symmetrical solutions high in $\mathrm{NaCl}$ and low in $\mathrm{HCO}_{3}^{-}$(Table I). Under these conditions, in the presence of a low $\mathrm{HCO}_{3}^{-}$ concentration in the lumen and the bath $(4 \mathrm{mM})$, it is unlikely that a significant chloride gradient could develop across the proximal tubule due to the preferential reabsorption of $\mathrm{HCO}_{3}^{-}$ (14). As shown in Fig. 6, formate in concentrations of 0.5 and $0.25 \mathrm{mM}$ in the bath and the lumen increased reversibly the reabsorption of fluid. Vte was not significantly different from zero $(-0.36 \pm 0.13 \mathrm{mV}$, mean $\pm \mathrm{SE})$. The absence of a significant lumen negative potential indicates that under these conditions the passive driving force for transepithelial chloride movement was minimal. Changes in Vte were not observed after addition of formate.

We also tested the effect of formate on fluid movement across the proximal convoluted tubule under conditions in which the $\mathrm{HCO}_{3}^{-}$concentration in the bathing and in the perfusion solutions was $20 \mathrm{mM}$. As shown in Fig. 7, in the presence of such high $\mathrm{HCO}_{3}^{-}$concentrations in the tubule fluid, addition of for-
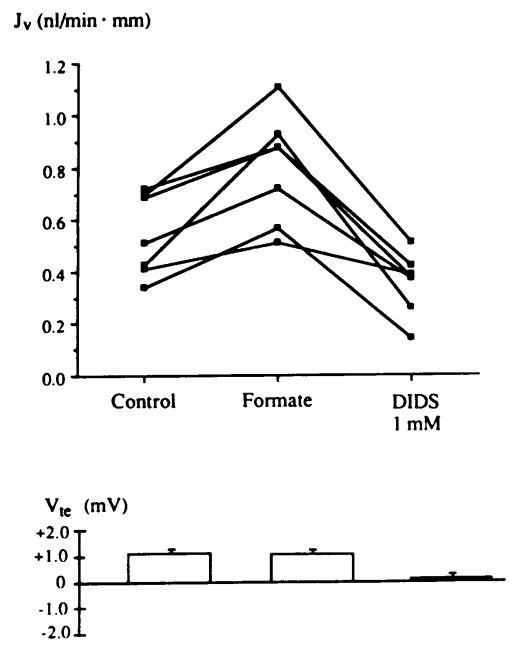

Figure 5. Effect of DIDS (1 $\mathrm{mM}$ in the perfusate) on $\mathrm{J}_{V}$ and $\mathrm{Vte}$ in the presence of formate $(0.5$ and $0.25 \mathrm{mM}$ ) in the perfusion fluid and the bath. S2 segments of the proximal tubule were perfused with a low $\mathrm{HCO}_{3}^{-}$solution, and $\mathrm{HCO}_{3}^{-}$solution. bathed in a $20 \mathrm{mM}$
$\mathrm{J}_{\mathrm{v}}(\mathrm{n} \mathrm{V} / \mathrm{min} \cdot \mathrm{mm})$

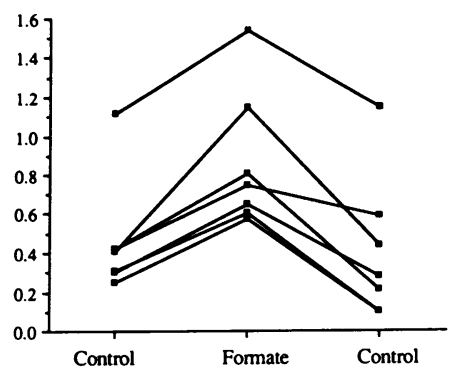

Figure 6. Effect of formate $(0.5$ and $0.25 \mathrm{mM})$ on $\mathrm{J}_{V}$ and $V$ te in the

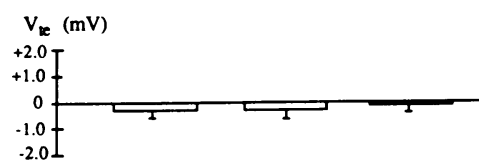
proximal convoluted tubule ( $\mathrm{S} 1$ segment), perfused and bathed with symmetrical low $\mathrm{HCO}_{3}^{-}$ solutions (4 mM).

mate, $0.5 \mathrm{mM}$ in bath and lumen, failed to stimulate significantly the reabsorption of fluid.

It has been pointed out elsewhere (8) that in order for chloride/formate exchange to drive significant amounts of $\mathrm{Cl}^{-}$into the cell, recycling of formate from the lumen to cell is required. One possible mechanism for such formate recycling into the cell is nonionic back diffusion of formic acid across the apical membrane (8). Hence inefficient recycling of formic acid at a high luminal pH could be responsible for the lack of effect of formate observed in tubules perfused with high $\mathrm{HCO}_{3}^{-}$solutions.

In order to test this hypothesis we performed $\mathrm{pH}$ measurements in the tubular fluid. As summarized in Table II, different $\mathrm{pH}$ levels were obtained in the perfusion experiments with different $\mathrm{HCO}_{3}^{-}$solutions. In proximal convoluted tubules perfused and bathed with symmetrical solutions containing $20 \mathrm{mM}$ $\mathrm{HCO}_{3}^{-}$, the $\mathrm{pH}$ of the perfusate decreased from 7.32 to 7.12 along the tubule. In this experimental setting, formate failed to stimulate water reabsorption. On the other hand, in experiments in which tubules were perfused and bathed with symmetrical low $\mathrm{HCO}_{3}^{-}$solutions ( $\left.4 \mathrm{mM} \mathrm{HCO}_{3}^{-}\right)$, the fall in luminal $\mathrm{pH}$ was greater, from 7.34 to 6.85 . Under this condition formate stimulated fluid reabsorption. These observations support the suggestion that $\mathrm{pH}$-sensitive recycling of formic acid across the apical membrane may be rate limiting for the stimulation of $\mathrm{NaCl}$ transport by formate in the proximal tubule.
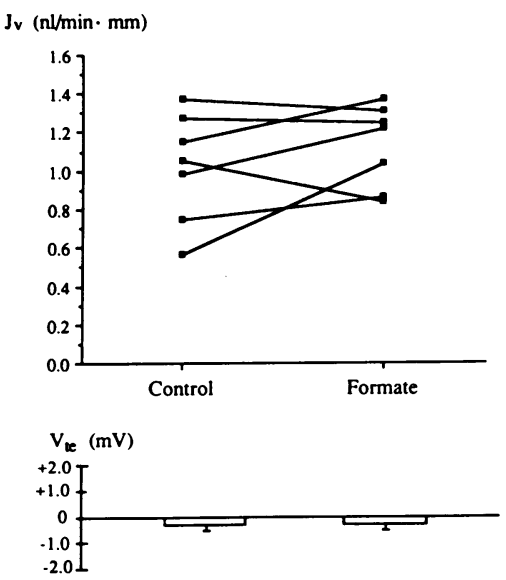

Figure 7. Effect of formate $(0.5 \mathrm{mM})$ on $\mathrm{J}_{V}$ and $V$ te in the proximal convoluted tubule (S1 segment), perfused and bathed with symmetrical high $\mathrm{HCO}_{3}^{-}$solutions (20 mM). 


\begin{tabular}{|c|c|c|c|c|c|}
\hline & $\begin{array}{l}\mathrm{pH} \text { in } \\
\text { perfusion fluid }\end{array}$ & $\begin{array}{l}\mathrm{pH} \text { in } \\
\text { collected fluid }\end{array}$ & $\mathrm{pH}$ in bath & Volume perfusion & $\begin{array}{l}\text { pH difference } \\
\text { (perfusion, collected fluid) }\end{array}$ \\
\hline & & & & $\mathrm{nl} / \mathrm{min}$ & \\
\hline $4 \mathrm{mM} \mathrm{HCO}_{3} \quad 1 \% \mathrm{CO}_{2}$ & $7.34 \pm 0.02$ & $6.85 \pm 0.05$ & $7.34 \pm 0.02$ & $13.18 \pm 1.40$ & 0.49 \\
\hline $20 \mathrm{mM} \mathrm{HCO}_{3} 5 \% \mathrm{CO}_{2}$ & $7.32 \pm 0.02$ & $7.12 \pm 0.03$ & $7.35 \pm 0.01$ & $12.97 \pm 1.9$ & 0.20 \\
\hline $4 \mathrm{mM} \mathrm{HCO}_{3} 1 \% \mathrm{CO}_{2}$ & $7.32 \pm 0.02$ & $6.82 \pm 0.02$ & $7.32 \pm 0.02$ & $13.12 \pm 0.9$ & 0.50 \\
\hline
\end{tabular}

Direct pH measurements were performed in seven paired convoluted proximal tubules, first perfused and bathed with symmetrical low $\mathrm{HCO}_{3}^{-}$ solutions, then with solutions containing $20 \mathrm{mM} \mathrm{HCO}_{3}^{-}$during the second period. A third period of recovery was performed in five tubules.

\section{Discussion}

The major question addressed by this study is whether formatecoupled transport of chloride contributes significantly to transepithelial chloride reabsorption in the proximal tubule. The chloride/formate exchange system and the nonionic diffusion of formic acid have recently been proposed by Karniski and Aronson to provide an electroneutral mechanism for secondary active $\mathrm{NaCl}$ reabsorption across the luminal membrane of the rabbit proximal tubule as depicted in Fig. 8 (8). Proton secretion via the $\mathrm{Na}^{+} / \mathrm{H}^{+}$exchanger allows formic acid to enter the cell by nonionic diffusion and maintains the intracellular formate concentration above electrochemical equilibrium across the luminal membrane. The outwardly directed electrochemical formate gradient represents the driving force for an active $\mathrm{Cl}^{-}$absorption via the chloride/formate exchanger. An interesting feature of this model concerns the recycling of formate from the lumen into the cell by nonionic diffusion. This mechanism potentially allows low concentrations of formate to drive significant amounts of $\mathrm{Cl}^{-}$from the tubular lumen into the cell despite the fact that formate is normally present in the plasma at levels of 0.1 to $1.4 \mathrm{mM}$ (15). Our experiments show that low concentrations of formate in the bath and the lumen stimulate isotonic volume reabsorption, and as predicted by the model, the increase in $\mathrm{NaCl}$ reabsorption is sensitive to anion-exchange inhibitors, ouabain, and luminal pH.

It is generally agreed that both passive and active transport contribute to $\mathrm{NaCl}$ reabsorption in the proximal tubule. Micropuncture experiments in the rat proximal tubule concluded that a major fraction of $\mathrm{NaCl}$ reabsorption is dependent on active transport processes because metabolic inhibitors reduce water

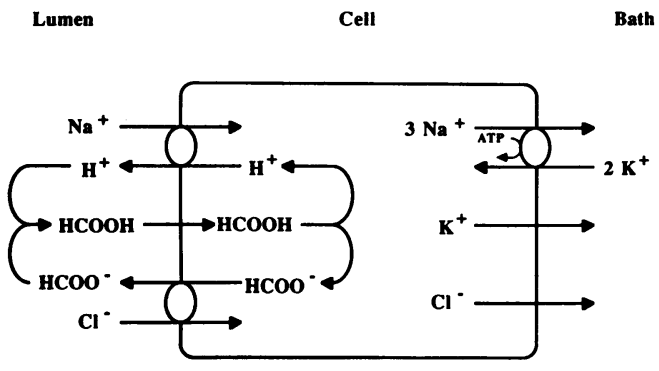

Figure 8. Model proposed by Karniski and Aronson (8) for the role of chloride/formate exchange in mediating Na-coupled active reabsorption of $\mathrm{Cl}$ across the luminal membrane of the proximal tubule cell. reabsorption by one half to two thirds in the presence of a normal chloride gradient $(6,14,16)$.

There are basically two ways that active $\mathrm{Na}^{+}$transport could affect chloride reabsorption. First, simple electrogenic $\mathrm{Na}^{+}$ transport could result in a lumen negative transepithelial potential difference that would drive passive chloride flux through the paracellular pathway. For instance, Cardinal et al. observed in the superficial proximal tubule that in the presence of a chloride gradient, ouabain shifts the positive transtubular potential in the positive direction, thus suggesting a component of simple electrogenic $\mathrm{Na}^{+}$transport (17). Similar results suggesting the presence of an electrogenic $\mathrm{Na}^{+}$transport have been reported in the rabbit pars recta (4). Second, active $\mathrm{Na}^{+}$transport may be coupled to secondary active transcellular $\mathrm{Cl}^{-}$transport. Recently, Baum and Berry, studying the electrical nature of $\mathrm{NaCl}$ transport in the rabbit proximal convoluted tubule, showed that ouabain decreased the active transport of $\mathrm{NaCl}$ without affecting the transepithelial potential (7). They concluded that active $\mathrm{NaCl}$ is electroneutral and transcellular.

In agreement with the later observations, our experiments presented in Fig. 4 indicate that reabsorption of $\mathrm{NaCl}$ in the $\mathrm{S} 2$ segment of the proximal tubule from a high-chloride solution is stimulated by formate and inhibited by ouabain. Both of these events occur without changes in the transepithelial potential. The active component of $\mathrm{NaCl}$ reabsorption inhibited by ouabain in these experiments is clearly electroneutral. Failure to find any difference in the Vte suggests that simple electrogenic $\mathrm{Na}^{+}$transport providing the electrochemical driving force for passive $\mathrm{Cl}^{-}$ reabsorption cannot account for the active, ouabain-sensitive component of $\mathrm{NaCl}$ reabsorption. These results differ from those reported by Schafer et al. for the pars recta (18) and suggest that intrinsic differences regarding the mechanism of $\mathrm{NaCl}$ reabsorption may exist along the proximal tubule. Instead this finding, in agreement with the result reported by Baum and Berry in the proximal convoluted tubule, supports the notion that the active component of $\mathrm{NaCl}$ transport is an electroneutral and transcellular process stimulated by formate. It should be pointed out that ouabain did not completely abolish the transepithelial water flux (Fig. 4). This ouabain-insensitive component of $J_{V}$ probably reflects the passive diffusion of $\mathrm{Cl}^{-}$due to the transepithelial $\mathrm{Cl}^{-}$gradient present in these experiments.

The experiments performed on the early proximal convoluted tubule (S1 segment) perfused and bathed with symmetrical high-chloride solutions are noteworthy in two respects. First they indicate that the increase in $J_{V}$ due to formate accounts only for a stimulation of the reabsorption of $\mathrm{NaCl}$. For instance, if formate would stimulate $\mathrm{HCO}_{3}^{-}$reabsorption, then the transepi- 
thelial $\mathrm{HCO}_{3}^{-}$flux, calculated from the difference in $\mathrm{J}_{V}$ before and after the addition of formate, would exceed the quantity of $\mathrm{HCO}_{3}^{-}$perfused into the tubular lumen. ${ }^{3}$ Second, these experiments constitute additional evidence for an active transcellular $\mathrm{NaCl}$ reabsorption stimulated by formate. Under these conditions where no passive driving forces are present for $\mathrm{Na}^{+}$and $\mathrm{Cl}^{-}$reabsorption, formate reversibly stimulated an electrically silent $\mathrm{NaCl}$ reabsorption.

A possible mode of sodium-coupled electroneutral $\mathrm{Cl}^{-}$ transport involves parallel ion exchangers such as $\mathrm{Na}^{+} / \mathrm{H}^{+}$and $\mathrm{Cl}^{-} / \mathrm{OH}^{-}$or $\mathrm{Cl}^{-} / \mathrm{HCO}_{3}^{-}$as identified in the Necturus proximal tubule (19). The presence of a $\mathrm{Cl}^{-} / \mathrm{HCO}_{3}^{-}$or $\mathrm{Cl}^{-} / \mathrm{OH}^{-}$exchange has not been reproducibly demonstrated in microvillus membrane vesicles isolated from rabbit proximal tubule cells $(20$, 21 , and Schwartz was unable to demonstrate the presence of this parallel anion exchange system in the intact rabbit proximal tubule (22). Chloride/formate exchanger in parallel with the $\mathrm{Na}^{+}$/ $\mathrm{H}^{+}$exchanger represents an alternative mechanism for transcellular sodium-coupled $\mathrm{Cl}^{-}$transport.

There are several possible ways for formate to stimulate water reabsorption in the proximal tubule. An increase in $\mathrm{NaCl}$ transport related to stimulation of cell metabolism can be excluded on the basis of the lack of effect of acetate on water reabsorption. Acetate is involved in generating substrates for cellular metabolism but does not share the chloride/formate exchanger (8). Moreover, luminal DIDS abolished the $\mathrm{NaCl}$ reabsorption stimulated by formate. This suggests that a specific anion exchange mechanism located at the luminal membrane is involved in the active $\mathrm{NaCl}$ reabsorption induced by formate.

Luminal DIDS also resulted in a drop in the transepithelial diffusion potential for $\mathrm{Cl}^{-}$and in a lower $\mathrm{J}_{V}$ observed in the presence of luminal DIDS $\left(0.35 \mathrm{nl} \cdot \mathrm{min}^{-1} \cdot \mathrm{mm}^{-1}\right)$ compared with the control condition $\left(0.54 \mathrm{nl} \cdot \mathrm{min}^{-1} \cdot \mathrm{mm}^{-1}, P=0.003\right)$ in Fig. 5. The reduction of $J_{V}$ below the control level could reflect the inhibition of another anion exchange like $\mathrm{HCO}_{3}^{-} / \mathrm{Cl}^{-}$involved in part of the volume reabsorption observed during the control period. An effect of 4-acetamido-4'-isothyocyanostilbene-2,2'-disulfonate on the paracellular permeability pathway similar to the effect of DIDS on Vte has been reported previously (13). The persistent volume reabsorption after the addition of DIDS in the lumen is likely due either to an incomplete inhibition of the luminal chloride/formate exchanger, as Karniski and Aronson reported a $60 \%$ inhibition of the chloride/ formate exchanger by $0.75 \mathrm{mM}$ DIDS in rabbit microvillus membrane vesicles (8), or to incomplete inhibition of passive intercellular $\mathrm{NaCl}$ reabsorption.

Since the quantity of $\mathrm{Cl}^{-}$reabsorbed greatly exceeds any possible net secretion of formate, formate must be recycled from the lumen into the cell for the formate/chloride exchanger to be operative in the active reabsorption of $\mathrm{Cl}^{-}$. The quantity of $\mathrm{Cl}^{-}$reabsorbed will therefore depend on formate's ability to be recycled back into the cell. One possible mechanism for the

3. Considering a luminal $\mathrm{pH}$ of 6.85 , as measured in the collected fluid of proximal convoluted tubules perfused and bathed with low $\mathrm{HCO}_{3}^{-}$ solution under control conditions (Tables I and II), this drop in luminal $\mathrm{pH}$ represents a reabsorptive flux of $\mathrm{HCO}_{3}^{-}$of $37 \mathrm{pmol} \cdot \mathrm{min}^{-1} \cdot \mathrm{mm}^{-1}$. If formate stimulates $\mathrm{HCO}_{3}^{-}$reabsorption, the increase in $\mathrm{J}_{V}$ would mean an additional $60 \mathrm{pmol} \cdot \mathrm{min}^{-1} \cdot \mathrm{mm}^{-1}$ of $\mathrm{HCO}_{3}^{-}$reabsorbed. Under this condition, $\mathrm{HCO}_{3}^{-}$reabsorption would be twofold greater than the quantity of $\mathrm{HCO}_{3}^{-}$perfused through the tubule. recycling of formate is the nonionic back diffusion of formic acid, as proposed by Karniski and Aronson. Accounting for the $\mathrm{pK}_{\mathrm{a}}$ of formate (3.9), the permeability coefficient for diffusion of formic acid across lipid bilayers $\left(10^{-2} \mathrm{~cm} \cdot \mathrm{s}^{-1}\right)(23)$, and assuming a luminal $\mathrm{pH}$ of 6.8 , as measured in the tubular fluid, and an intracellular $\mathrm{pH}$ of 7.2 , the calculated lumen-to-cell unidirectional flux of formic acid is $\sim 30 \mathrm{pmol} \cdot \mathrm{min}^{-1} \cdot \mathrm{mm}^{-1}$ when the concentration of formate in the lumen was $0.5 \mathrm{mM}$. The magnitude of this flux is sufficient to sustain significant volume reabsorption in the proximal tubule.

On the other hand, we observed in the early proximal convoluted segment that formate failed to stimulate $\mathrm{NaCl}$ reabsorption when these tubular segments were perfused with a high $\mathrm{HCO}_{3}^{-}$solution (Fig. 5), whereas in those perfused with low $\mathrm{HCO}_{3}^{-}$solution formate did result in significant stimulation of $\mathrm{J}_{V}$ (Fig. 6). One possible explanation is that the tubular fluid is less effectively acidified during perfusion with a solution of a high buffer content ( $20 \mathrm{mM}$ bicarbonate) than with a solution with a low buffer content ( $4 \mathrm{mM}$ bicarbonate), so that the nonionic back diffusion of formic acid is compromised enough to render the chloride/formate mechanism ineffective.

The pH measurements of the tubular fluid (Table II) indicate that the absence of formate-induced $\mathrm{NaCl}$ reabsorption when tubules were perfused with a high bicarbonate perfusate can be correlated with a smaller drop in luminal $\mathrm{pH}$. This observation supports the hypothesis that nonionic back diffusion of formic acid into the cell is essential for maintaining an intracellular formate concentration high enough to drive active $\mathrm{Cl}^{-}$uptake into the cell. However, we cannot exclude the possibility that $\mathrm{HCO}_{3}^{-}$directly inhibited the chloride/formate exchanger when tubules were perfused with $20 \mathrm{mM} \mathrm{HCO}_{3}^{-}$.

Even if the formate/chloride exchanger represents an important step in the active electroneutral $\mathrm{NaCl}$ reabsorption in the proximal tubule, it is still not clear how $\mathrm{Cl}^{-}$is reabsorbed in the absence of added formate and any electrochemical driving force. For example, in the experiments illustrated in Fig. 6, the small negative transepithelium potential $(-0.3 \mathrm{mV})$ can passively drive at most $10 \%$ of the $\mathrm{Cl}^{-}$reabsorption observed during the control condition, assuming a permeability coefficient $\left(P_{\mathrm{C}}\right)$ for chloride of $0.73 \cdot 10^{-4} \mathrm{~cm} \cdot \mathrm{s}^{-1}$, as reported in the rabbit proximal tubule by Schafer et al (4). One possibility is that the intracellular production of formate is sufficient to sustain a physiologically relevant transcellular $\mathrm{Cl}^{-}$transport. The concentration of formate produced within proximal tubule cells is unknown.

As discussed previously, another possibility is that $\mathrm{Cl}^{-} / \mathrm{HCO}_{3}^{-}$exchange takes place. Certainly it is possible that transport systems functional in the intact cell could be inactive in isolated membrane vesicles. Finally, the low apical conductance to chloride in the rabbit proximal tubule (24), and the probability that intracellular $\mathrm{Cl}^{-}$activity is above its electrochemical equilibrium, as in the rat proximal tubule (25), makes passive diffusion of $\mathrm{Cl}^{-}$across the luminal membrane very unlikely. Accordingly the mechanism of the baseline electroneutral $\mathrm{Cl}^{-}$absorption in the absence of added formate requires further investigation.

In summary, we have shown that formate in submillimolar concentrations stimulates active electroneutral $\mathrm{NaCl}$ transport in the $\mathrm{S} 1$ and $\mathrm{S} 2$ segments of the proximal tubules of the rabbit kidney. A specific anion exchange located at the luminal membrane is involved in this transport mechanism. Our results are compatible with the model already proposed where chloride/ formate exchange in parallel with $\mathrm{Na}^{+} / \mathrm{H}^{+}$antiport allows an 
electroneutral sodium-coupled, chloride-active reabsorption. This mechanism of active $\mathrm{NaCl}$ transport contributes significantly to the transepithelial reabsorption of $\mathrm{NaCl}$ in the proximal tubule.

\section{Acknowledgments}

We are extremely grateful to Dr. S. K. Agulian for generously supplying us with the manufacture of the $\mathrm{pH}$-sensitive electrodes.

This work was supported by National Institutes of Health grants AM-17433 and AM-33793.

\section{References}

1. Burg, M. B. 1986. Renal handling of sodium, chloride, water, amino acids and glucose. In The Kidney. B. M. Brenner and F. C. Rector, editors. W.B. Saunders Company; Philadelphia. Third ed. 145-176.

2. Giebisch, G., and P. S. Aronson. 1986. The proximal nephron. In Physiology of Membrane Disorders. T. E. Andreoli, J. F. Hoffman, D. D. Fanestil, and S. G. Schultz, editors. Plenum Medical Book Company, New York and London. Second ed. 669-700.

3. Boulpaep, E. L. 1971. Electrophysiological properties of the proximal tubule: importance of cellular and intercellular transport pathways. In Electrophysiology of Epithelial Cells. G. Giebisch, editor. F. K. Schattauer Verlag, Stüttgart. 199-246.

4. Schafer, J. A., S. L. Troutman, and T. E. Andreoli. 1974. Volume reabsorption, transepithelial potential differences, and ionic permeability properties in mammalian superficial proximal straight tubules. J. Gen. Physiol. 64:582-607.

5. Alpern, R. J., K. J. Howlin, and P. Preisig. 1985. Active and passive components of chloride transport in the rat proximal convoluted tubule. J. Clin. Invest. 76:1360-1366.

6. Green, R., J. H. V. Bishop, and G. Giebisch. 1979. Ionic requirements of proximal tubular sodium transport. III. Selective luminal ion substitution. Am. J. Physiol. 236:F268-F277.

7. Baum, M., and C. A. Berry. 1984. Evidence for neutral transcellular $\mathrm{NaCl}$ transport and neutral basolateral chloride exit in the rabbit proximal convoluted tubule. J. Clin. Invest. 14:205-211.

8. Karniski, L. P., and P. S. Aronson. 1985. Chloride/formate exchange with formic acid recycling: a mechanism for active chloride transport across epithelial membranes. Proc. Natl. Acad. Sci. USA. 82: 6362-6365.

9. Burg, M. B., J. Grantham, M. Abramow, and J. Orloff. 1966. Preparation and study of fragments of single rabbit nephrons. Am. J. Physiol. 210:1293-1298.
10. Biagi, B. A., and G. Giebisch. 1979. Temperature dependence of transepithelial potential in isolated and perfused proximal tubules. Am. J. Physiol. 236:F302-F310.

11. Koeppen, B. M., and S. I. Helman. 1982. Acidification of luminal fluid by the rabbit cortical collecting tubule perfused in vitro. Am. J. Physiol. 242:F521-F531.

12. Snedecor, G. W., and W. G. Cochran. 1980. Statistical Methods. Iowa State University Press, Ames, IA. Seventh ed. 1-106.

13. Weinstein, S. W., and A. Williams. 1983. Effect of amiloride and SITS on $\mathrm{NaCl}$ permeability in isolated perfused proximal tubule. Kidney Int. 23:269. (Abstr.)

14. Green, R., R. J. Moriarty, and G. Giebisch. 1981. Ionic requirements for proximal tubule fluid reabsorption: flow dependence of fluid transport. Kidney Int. 20:580-587.

15. Annison, E. F. 1954. Studies on the volatile fatty acids of sheep blood with special reference to formic acid. Biochem. J. 58:670-680.

16. Chantrelle, B. M., M. G. Cogan, and F. C. Rector, Jr. 1985. Active and passive components of $\mathrm{NaCl}$ absorption in the proximal tubule of the rat kidney. Mineral. Electrolyte Metab. 11:209-214.

17. Cardinal, J., M. D. Lutz, M. B. Burg, and J. Orloff. 1975. Lack of relationship of potential difference to fluid reabsorption in the proximal tubule. Kidney Int. 7:94-102.

18. Schafer, J. A., C. S. Patlak, and T. E. Andreoli. 1975. A component of fluid absorption linked to passive ion flows in the superficial pars recta. J. Gen. Physiol. 66:445-471.

19. Seifter, J. L., and P. S. Aronson. 1984. Cl transport via anion exchange in Necturus renal microvillus membranes. Am. J. Physiol. 247: F888-F895.

20. Seifter, J. L., R. Knickelbein, and P. S. Aronson. 1984. Absence of $\mathrm{Cl}-\mathrm{OH}$ exchange and $\mathrm{NaCl}$ cotransport in rabbit microvillus membranes vesicles. Am. J. Physiol. 247:F753-F759.

21. Warnock, D. G., and V. J. Yee. 1981. Chloride uptake in brush border membrane vesicles isolated from rabbit renal cortex. Coupling to proton gradients and $\mathrm{K}$ diffusion potentials. J. Clin. Invest. 67:103115 .

22. Schwartz, G. J. 1983. Absence of $\mathrm{Cl}^{-} / \mathrm{OH}^{-}$or $\mathrm{Cl}^{-} / \mathrm{HCO}_{3}^{-}$exchange in the rabbit proximal tubule. Am. J. Physiol. 245:F462-F469.

23. Walter, A., and J. Gutknecht. 1984. Monocarboxylic acid permeation through lipid bilayer membranes. J. Membr. Biol. 77:255-264.

24. Lapointe, J. Y., R. Laprade, and J. Cardinal. 1986. Characterization of the apical membrane ionic permeability of the rabbit proximal convoluted tubule. Am. J. Physiol. 250:F339-F347.

25. Cassola, A. C., M. Mollenhauer, and E. Fromter. 1983. The intracellular chloride activity of rat kidney proximal tubular cells. Pfluegers Arch. Eur. J. Physiol. 399:259-265. 